\title{
Inducible nitric oxide synthase (iNOS) expression in monocytes during acute Dengue Fever in patients and during in vitro infection Patrícia CF Neves-Souza ${ }^{\dagger 1}$, Elzinandes L Azeredo ${ }^{\dagger 1}$, Sonia MO Zagne ${ }^{2}$, Rogério Valls-de-Souza ${ }^{3}$, Sonia RNI Reis ${ }^{1}$, Denise IS Cerqueira ${ }^{1}$, Rita MR Nogueira ${ }^{1}$ and Claire F Kubelka*1
}

Address: ${ }^{1}$ Departmento de Virologia, Instituto Oswaldo Cruz Fundação Oswaldo Cruz, Av. Brasil, 4365, CEP 21040-360 Rio de Janeiro, RJ, Brazil, ${ }^{2}$ Departamento de Clínica Médica, Hospital Antonio Pedro, Universidade Federal Fluminense, Niterói, RJ, Brazil and ${ }^{3}$ Instituto de Pesquisas Evandro Chagas, Fundação Oswaldo Cruz, Av. Brasil, 4365, CEP 21040-360 Rio de Janeiro, RJ, Brazil

Email: Patrícia CF Neves-Souza - patneves@ioc.fiocruz.br; Elzinandes L Azeredo - elzinandes@yahoo.com.br;

Sonia MO Zagne - sonia_maris@yahoo.com.br; Rogério Valls-de-Souza - rvalls@uol.com.br; Sonia RNI Reis - sonireis@ioc.fiocruz.br;

Denise IS Cerqueira - denisece@ioc.fiocruz.br; Rita MR Nogueira - rita@ioc.fiocruz.br; Claire F Kubelka* - claire@ioc.fiocruz.br

* Corresponding author †Equal contributors

Published: 18 August 2005

BMC Infectious Diseases 2005, 5:64 doi:10.1 186/147/-2334-5-64

This article is available from: http://www.biomedcentral.com/I47I-2334/5/64

(c) 2005 Neves-Souza et al; licensee BioMed Central Ltd.

This is an Open Access article distributed under the terms of the Creative Commons Attribution License (http://creativecommons.org/licenses/by/2.0), which permits unrestricted use, distribution, and reproduction in any medium, provided the original work is properly cited.
Received: 03 October 2004

Accepted: 18 August 2005

\begin{abstract}
Mononuclear phagocytes are considered to be main targets for Dengue Virus (DENV) replication. These cells are activated after infection, producing proinflammatory mediators, including tumournecrosis factor- $\alpha$, which has also been detected in vivo. Nitric oxide (NO), usually produced by activated mononuclear phagocytes, has antimicrobial and antiviral activities.
\end{abstract}

\section{Methods}

The expression of DENV antigens and inducible nitric oxide synthase (iNOS) in human blood isolated monocytes were analysed by flow cytometry using cells either from patients with acute Dengue Fever or after DENV-I in vitro infection. DENV-I susceptibility to iNOS inhibition and NO production was investigated using $N^{G}$-methyl L-Arginine (NGMLA) as an iNOS inhibitor, which was added to DENV-I infected human monocytes, and sodium nitroprussiate (SNP), a NO donor, added to infected $\mathrm{C} 6 / 36$ mosquito cell clone. Viral antigens after treatments were detected by flow cytometry analysis.

\section{Results}

INOS expression in activated monocytes was observed in 10 out of 21 patients with Dengue Fever and was absent in cells from ten healthy individuals. DENV antigens detected in 25 out of 35 patients, were observed early during in vitro infection ( 3 days), significantly diminished with time, indicating that virus replicated, however monocytes controlled the infection. On the other hand, the iNOS expression was detected at increasing frequency in in vitro infected monocytes from three to six days, exhibiting an inverse relationship to DENV antigen expression. We demonstrated that the detection of the DENV-I antigen was enhanced during monocyte treatment with NGMLA. In 
the mosquito cell line $\mathrm{C} 6 / 36$, virus detection was significantly reduced in the presence of SNP, when compared to that of untreated cells.

\section{Conclusion}

This study is the first to reveal the activation of DENV infected monocytes based on induction of iNOS both in vivo and in vitro, as well as the susceptibility of DENV-I to a NO production.

\section{Background}

Dengue viruses (DENV) have been detected in several lymphoid organs originating from fatal cases of hemorrhagic disease, mainly in cells from the mononuclear phagocyte lineage [1]. Nevertheless, the frequency of disseminated virus detection in autopsies is low and microscopic injury is not sufficient to justify death during the Dengue Hemorrhagic Fever (DHF) or Dengue Shock Syndrome (DSS). It is believed that disease severity is a result of an immunopathological response leading to hemorrhagic and vasodynamic alterations and shock.

Mononuclear phagocytes have been considered as main targets for DENV replication [2,3] and recently the virus was detected in dendritic cells originating from one individual 24 hours post DENV infection [4,5]. Morens et al. [6] have shown strain differences of DENV, originating either from mild or severe cases, with respect to their growth in human monocytes, suggesting that characteristics inherent to virus genome and replication were related with disease severity. Viral RNA was detected by RT-PCR in peripheral blood leukocytes [7] in humans during infection and DENV antigens were present in circulating monocytes [8], Kupffer cells and macrophages from different organs such as liver, spleen and lungs [9].

Pathogenesis may consist of virus penetration into monocytes or dendritic cells, cell activation and synthesis induction of cytokines, arachdonic acids and very likely nitric oxide. These factors would be involved not only in generating dengue disease [10] but also in the elimination of viruses [11].

The in vivo activation of mononuclear phagocytes by interferon (IFN)- $\gamma$ during DENV infection can be expected, since this cytokine is detected in serum during the acute phase $[12,13]$ and is also produced by peripheral leukocytes from patients with previous dengue records [14]

The in vitro production of IFN- $\alpha, \beta$, interleukin- 6 and tumour-necrosis factor (TNF)- $\alpha$ by infected fibroblasts and/or macrophages was described [15] as well as the production of platelet activating factors [16]. Recently, viral titres during infection were correlated with the production of prostaglandin $E_{2}$, which is known to be vasoactive [17].

Considering that dengue is an acute and short-termed disease, and IFN- $\alpha, \beta$ and TNF- $\alpha$ are molecules that induce antiviral defence mechanisms [11], it is conceivable that DENV replication is greatly inhibited in mononuclear phagocytes, although inflammatory reactions may be activated as well. It is well known that NO is produced by IFN- $\gamma$ activation of monocytes [18] and has antiviral activities against Herpes Simplex Viruses, Epstein Bar Virus and some Coxsackie and Tick-borne encephalitis viruses [16]. NO levels were found to be increased in patients with dengue [19] or in vitro infected Kupffer cells [20], however the production has not been detected in infected monocytes in culture [21].

The aim of this research is to investigate iNOS monocyte induction during acute DENV infection in patients and after in vitro infection by DENV-1. We demonstrated that monocytes isolated from several patients became activated and express iNOS, which leads to the production of NO by the cell. DENV-1 was susceptible to a NO donor treatment and, in addition, virus was detected at higher rates in infected cells after iNOS inhibition, indicating that NO might play a substantial role in controlling DENV-1 infection of monocytes in culture and in vivo during natural infection.

\section{Methods \\ Patients and laboratory diagnosis}

Blood samples were obtained from DENV infected patients in April 2000 in Foz do Iguaçu, PR, and from February to April 2001 and January to March 2002 in Niterói, RJ, Brazil. Patients were diagnosed based on clinical grounds as Dengue Fever (fever, headache, retro-orbital pain, mialgias, arthralgias, rash and prostration); some had hemorrhagic manifestations, platelet counts under $100,000 / \mathrm{mm}^{3}$, hypotension receiving parenteral hydration and hospitalisation. The diagnosis of DENV infection was confirmed by anti-dengue enzyme-linked immunosorbent assay (ELISA)-IgM, or virus isolation. Informed written consent, approved by Fundação Oswaldo Cruz 
Ethical Committee under Nr\#111/00, was obtained from all dengue patients prior to blood draw.

\section{Cell cultures}

Aedes albopictus $\mathrm{C} 6 / 36$ cell clone was grown as monolayers at $34^{\circ} \mathrm{C}$ on Leibovitz medium (L-15) supplemented with $200 \mathrm{mM}$ glutamine, $1 \%$ non-essential amino acids solution, $19 \%$ tryptose phosphate broth, $100 \mathrm{U} / \mathrm{ml}$ penicillin, $10 \mu \mathrm{g} / \mathrm{ml}$ streptomycin and 5\% foetal calf serum (FCS).

\section{Preparation of virus stock and virus titration}

DENV serotype 1, strain 16007 was provided by Dr. SB Halstead (Naval Medical Research Center, USA). Virus was titrated by serial dilution cultures in microtiter plates and detected by immunofluorescence as previously described [22]. Virus titre was calculated as 50 percent tissue culture infectious dose or $\mathrm{TCID}_{50} / \mathrm{ml}[23,24]$. Inactivated virus was prepared by incubating the inoculum for 24 hours at $37^{\circ} \mathrm{C}$ and treating it with UV light $(60 \mathrm{~Hz}$, with distance of $20 \mathrm{~cm}$ ) for 1 hour. Virus stock used was at a concentration of $3.18 \times 10^{7} \mathrm{TCID}_{50} / \mathrm{ml}$.

\section{Preparation of human peripheral blood mononuclear leukocytes (PBMLs)}

Mononuclear leukocytes were obtained from heparinised venous blood originating from either DENV-infected patients or dengue seronegative adult donors. Cells were isolated through density gradient centrifugation (350 g, 20 minutes in Ficoll-Paque Plus Amersham Biosciences Corp, Piscataway, USA). Cells were suspended in RPMI 1640 supplemented with $200 \mathrm{mM}$ glutamine, $100 \mathrm{U} / \mathrm{ml}$ penicillin, $10 \mu \mathrm{g} / \mathrm{ml}$ streptomycin and 10\% FCS and afterwards incubated at $37^{\circ} \mathrm{C}$ under humid atmosphere with $5 \% \mathrm{CO}_{2}$. Cells isolated from patients with acute dengue were suspended in supplemented RPMI 1640 containing an additional 10\% DMSO and 50\% FCS and maintained in liquid nitrogen.

\section{Infection of adherent PBMLs and treatment with an iNOS inhibitor}

Infections were performed on 24-well plates. Freshly isolated PBML suspended in RPMI 1640 medium and supplemented with $10 \%$ FCS were seeded at $2 \times 10^{6} \mathrm{cells} /$ well. After an 18 hour-incubation, adherent cells were enriched by washing away unattached cells twice. Inoculum was diluted in $1 \mathrm{ml}$ medium containing a multiplicity of infection approximately of $8 \mathrm{TCID}_{50}$ /adherent cell DENV-1. After a 2 hour-incubation for adsorption, $1 \mathrm{ml}$ medium was added to achieve 10\% FCS. After an 18 hour-incubation, all culture medium containing virus was removed and cultures were further incubated with fresh medium for up to 6 days. In some experiments the iNOS inhibitor, $\mathrm{N}^{\mathrm{G}}$-methyl L-Arginine ( ${ }^{\mathrm{G}} \mathrm{MLA}$ ), was added at a final concentration of $400 \mu \mathrm{M}$. Wells were set in triplicates for each different parameter in culture. Cell viability was deter- mined in culture by Trypan blue exclusion during 6 days. Duplicates of cell control, inactivated and infectious DENV were assayed. Viability ratios were calculated by dividing cell counts from each day by counts made just after virus adsorption.

Infection of C6/36 cell line and treatment with a NO donor Infections were performed on 24-well plates. C6/36 were seeded at $2 \times 10^{5}$ cells/well in medium with 5\% FCS and allowed to form a monolayer for $24 \mathrm{~h}$ at $34^{\circ} \mathrm{C}$. Cell supernatant was removed and adherent cells were washed twice with medium without FCS. Wells were filled with $1 \mathrm{ml}$ fresh medium containing DENV-1 or only medium in a 1:10 dilution from initial inoculum containing a multiplicity of infection of $1.59 \mathrm{TCID}_{50} /$ cell for DENV-1. After a 90 minute-adsorption, $1.0 \mathrm{ml}$ medium was added to achieve $2 \%$ FCS, containing sodium nitroprussiate (SNP), a NO donor, resulting in final concentrations of 10 or 100 $\mu \mathrm{M}$ [25]. Viruses were allowed to grow for two days in incubated cultures. Triplicate wells were set for each culture parameter. Viability of treated cells was confirmed by Trypan blue exclusion or propidium iodine uptake.

\section{Virus labelling of infected C6/36 cells, single and double labelling of infected adherent PBMLs for flow cytometry analysis}

Cells were recovered by scratching with plastic microtip using cold medium and were set at $1 \times 10^{6} /$ microtube; they were centrifuged ( $350 \mathrm{~g}, 5 \mathrm{~min}$ ) and washed once with $1 \mathrm{ml}$ PBS pH 7.4 with $2 \%$ FCS and $0,01 \% \mathrm{NaN}_{3}$. Surface labelling was performed with FITC-labelled antibodies to CD14 (DAKO, Denmark, 1:100 dilution) for 45 min directly on adherent viable PBMLs under ice bath. This was done to confirm that $~ 95 \%$ of the monocyte gated cells would be CD14+ on the infection day. Intracellular staining after infection was performed according to previously described [26] with slight modifications. Briefly, it required a fixation with $0.5 \mathrm{ml}$ cold paraformaldehyde at $4 \%$ in PBS for 10 min and, after centrifugation, membrane permeabilization was carried out with $1 \mathrm{ml}$ $0.1 \%$ saponine in PBS with FCS and $\mathrm{NaN}_{3}$. Monoclonal antibody Dengue Complex-reactive (Chemicon, USA, 1:200 dilution in PBS with saponine, FCS and $\mathrm{NaN}_{3}$ ) was added to cells for a 60-minute incubation. Cells were washed once with $1 \mathrm{ml}$ PBS with FCS and $\mathrm{NaN}_{3}$ and further incubated with anti-mouse IgG labelled with PE or FITC (DAKO, USA, 1:50 dilution in PBS with saponine, FCS and $\mathrm{NaN}_{3}$ ) for 30 minutes. After washing, infected adherent PBMLs were further incubated with FITClabelled antibody to iNOS (B\&D Transduction Laboratories, USA, 1:100 dilution) for 45 minutes. Alternatively, for double staining CD14 and DENV, cells were firstly labelled with PE-labelled antibodies to CD14 (DAKO at dilution $1: 100$ ) for 30 minutes $4^{\circ} \mathrm{C}$, washed, fixed with $0,5 \mathrm{ml}$ cold $2 \%$ paraformaldehyde for 10 minutes and, 
after centrifugation, membrane permeabilization was carried out with $1 \mathrm{ml} 0.1 \%$ saponine PBS with FCS and $\mathrm{NaN}_{3}$ and further labelled with Alexa 654 - labelled monoclonal antibody to Dengue for 30 minutes. Matching isotype antibodies were used for DENV and iNOS labelings. Finally cells were washed twice, ressuspended in $1 \%$ paraformaldehyde and kept at $4{ }^{\circ} \mathrm{C}$ up to 3 days until acquisition by flow cytometry. Cells were acquired $(10,000$ events for cell lines and 5,000 for gated monocytes) on a FACS ${ }^{\circledast}$ Calibur flow cytometer (Beckon \& Dickinson, USA) and analysed using FlowJo Software (TreeStar Inc., CA, USA). Isotype-matched antibodies were used as a negative control for all stainings.

\section{Statistical analyses}

Two-way Student's $t$ test was performed using GraphPad Prism version 4.02 for Windows, GraphPad Software (San Diego, CA, USA, http://www.graphpad.com) in order to determine the significance of differences in percentages of virus labelling found in cells infected under various conditions. Altered parameters were considered significant when $\mathrm{P}<0.05$.

Labelled cell rates in healthy donors were firstly tested for normality using the Prism program (values passed the normality test of Kolmogorow-Smirnov) and then cell patient frequencies were tested for sample positivity by Student's $t$-Distribution $\left(t_{n-1}=10, \alpha=0.025=2.228\right.$ or $t_{n-1}=9$, $\alpha=0.025=2.262$ ) calculating a referential limit value for negativity, according to the following formula: Average of values from control samples + [Standard Deviation of values from control samples $\left.X t_{(n-1 ; \alpha=0.025)}\right]$. Determinations above referential limit values were considered positive.

\section{Results \\ Characterization of target cells for DENV and iNOS expression in peripheral blood mononuclear leukocytes (PBMLs) originating from patients with Dengue Fever}

Previous reports demonstrated human monocytes as targets for DENV in cultures [1,27]. Therefore, monocyte and lymphocyte subsets present in PBMLs originated from patients with acute Dengue Fever were analysed by flow cytometry (FACS). Figure 1 displays the cell size and granularity profiles of PBMLs from a healthy donor (Figure $1 \mathrm{~A})$ and a dengue patient (Figure 1C). CD14+ gated cells were selected (Figure 1B) and plotted as logical monocyte gate in the FSCxSSC dot plot (R1 in Figure 1C). Monocyte (R1) and lymphocyte (R2) gates selected were used for further studies. Approximately 95\% cells of the R1 are CD14+ cells.

The monocyte and lymphocyte profile by FACS after DENV and iNOS immune-labelling were studied. Representative dot plots of DENV Antigens (Ag) and iNOS positive detection in monocytes from dengue patients
(Figures $1 \mathrm{E}$ and $1 \mathrm{H}$, respectively) are compared to monocytes from healthy individuals (Figures $1 \mathrm{D}$ and $1 \mathrm{G}$ ) and lymphocytes from patients (Figures $1 \mathrm{~F}$ and 1I). Patient monocytes presented DENV-Ag during the first eleven days of disease onset (Figures 1E and 2A) compared to control monocytes (Figures 1D and 2A). Patient cells collected at later stages of disease did not display detectable viral antigen (data not shown). Among the 35 dengue patients 25 expressed DENV-Ag above the referential limit value for negativity in the Student's $t$-Distribution and no difference was detected between early (1-5 days) and late (6-11 days) infection. Among 22 patients tested for iNOS expression (Figures $1 \mathrm{H}$ and $2 \mathrm{~B}$ ), 10 were positive as compared to controls (Figures $1 \mathrm{G}$ and $2 \mathrm{~B}$ ). Cells from the lymphocyte gate do express neither DENV-Ag $(0.80 \pm 0.77 \%)$ nor iNOS $(3.7 \pm 2.57 \%)$ (Figures $1 \mathrm{~F}$ and $1 \mathrm{I}$, respectively). The highest incidence of iNOS activation was from 6 to 10 days of disease ( 8 out of 20 patients). Among 11 patients with platelet counts $<100,000 / \mathrm{mm}^{3}$, six had iNOS+ cells above the referential limit value for negativity. Seven of these patients also had hypotension, were hospitalised and submitted to parenteral rehydration. Among 11 patients with normal platelet levels merely 4 had significantly elevated iNOS ${ }^{+}$cell ratios. INOS expression, present in a significant frequency among dengue patients, could not be associated with severity in this sampling.

\section{Characterization of DENV target cells, DENV-Ag detection and iNOS expression in monocytes after in vitro infection} Adherent human PBMLs were incubated for 3-6 days with infectious and inactivated DENV and evaluated for presence of DENV-Ag and iNOS expression. Cell viability was determined daily by Trypan blue exclusion. After 3 days of culture, cells incubated with the inactivated virus remained $42 \pm 7 \%$ viable and with infectious virus $42 \pm$ $23 \%$ viable as compared to the day 0 . On day $637 \pm 2 \%$ cells were viable for inactivated and $44 \pm 3 \%$ for infectious virus, showing no differences between the two virus incubations. Control cell rates of viability were higher, $58 \pm$ $8 \%$ at day 3 and $69 \pm 19 \%$ at day 6 . Although infectious viruses may not be crucial in increasing monocyte mortality, viral antigens alter cell viability.

Kinetics of virus detection in mononuclear phagocytes varies according to virus strain and multiplicity of infection (MOI) used (Cologna et al., 2003). At the MOI used here for DENV-1 strain 16007 (8 TCID To $^{\text {adherent cell) }}$ preliminary results displayed low rates of infection on the first day (in average $17 \pm \%$ ), increasing at day 2 (average $31 \%$ ). No iNOS labelling was detected on these first days of infection. Therefore, experiments were performed using infections from 3 to 6 days.

Figure 3B shows an image obtained under confocal microscopy in a field with a high frequency of infected adherent 


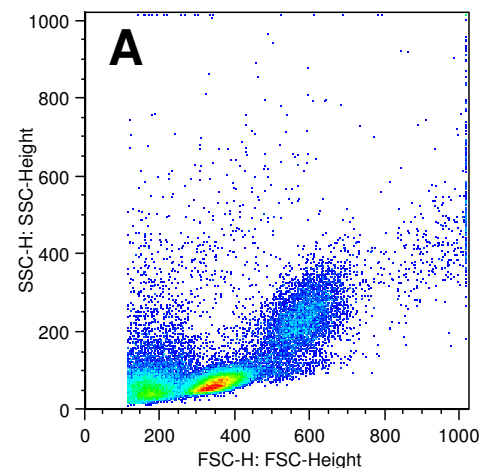

Control Monocytes
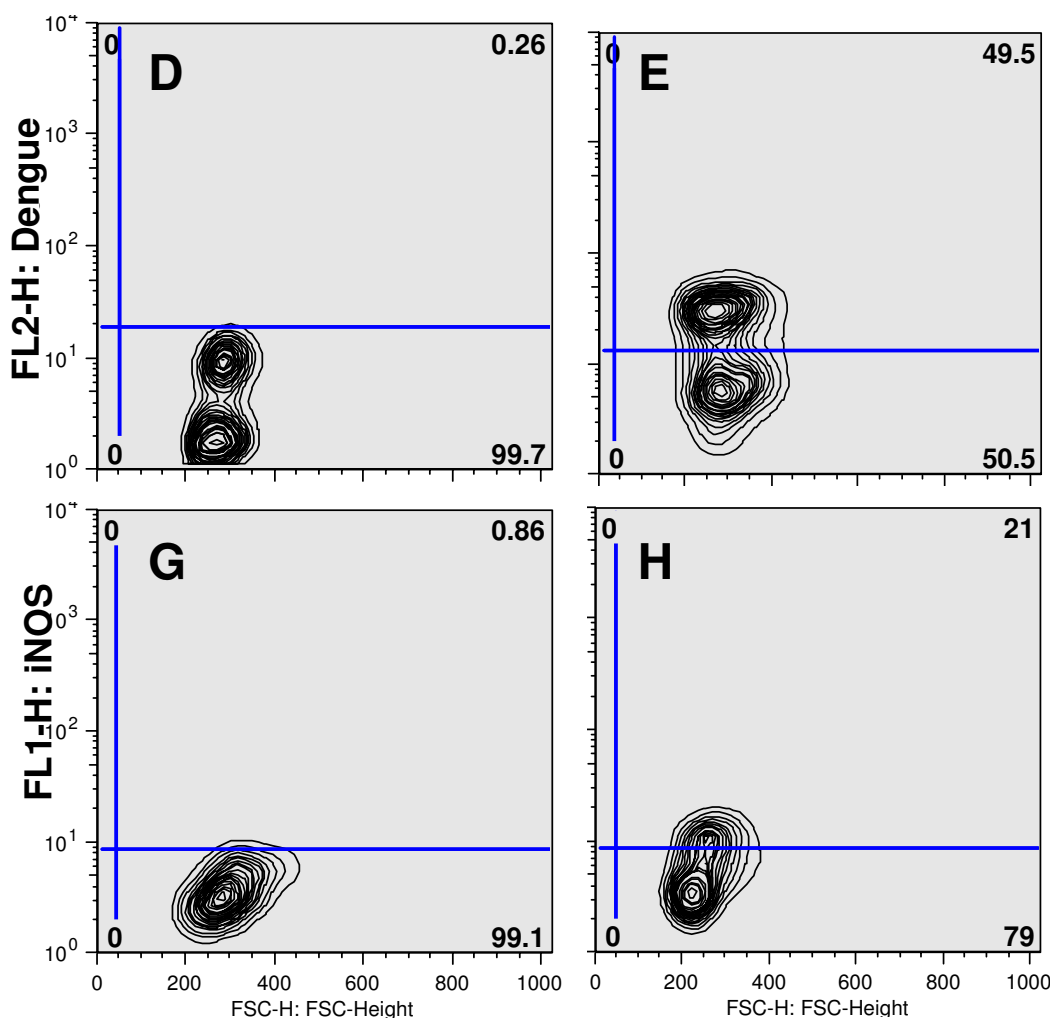

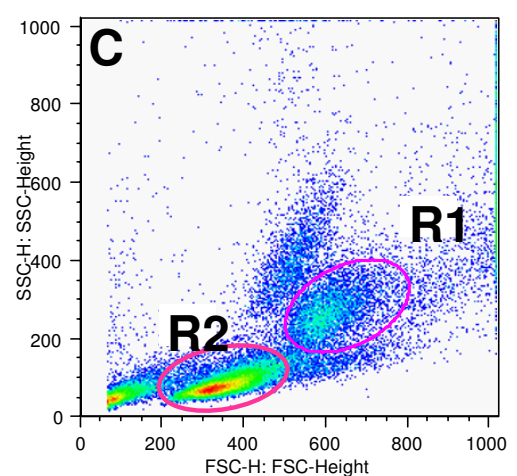

Patient Lymphocytes
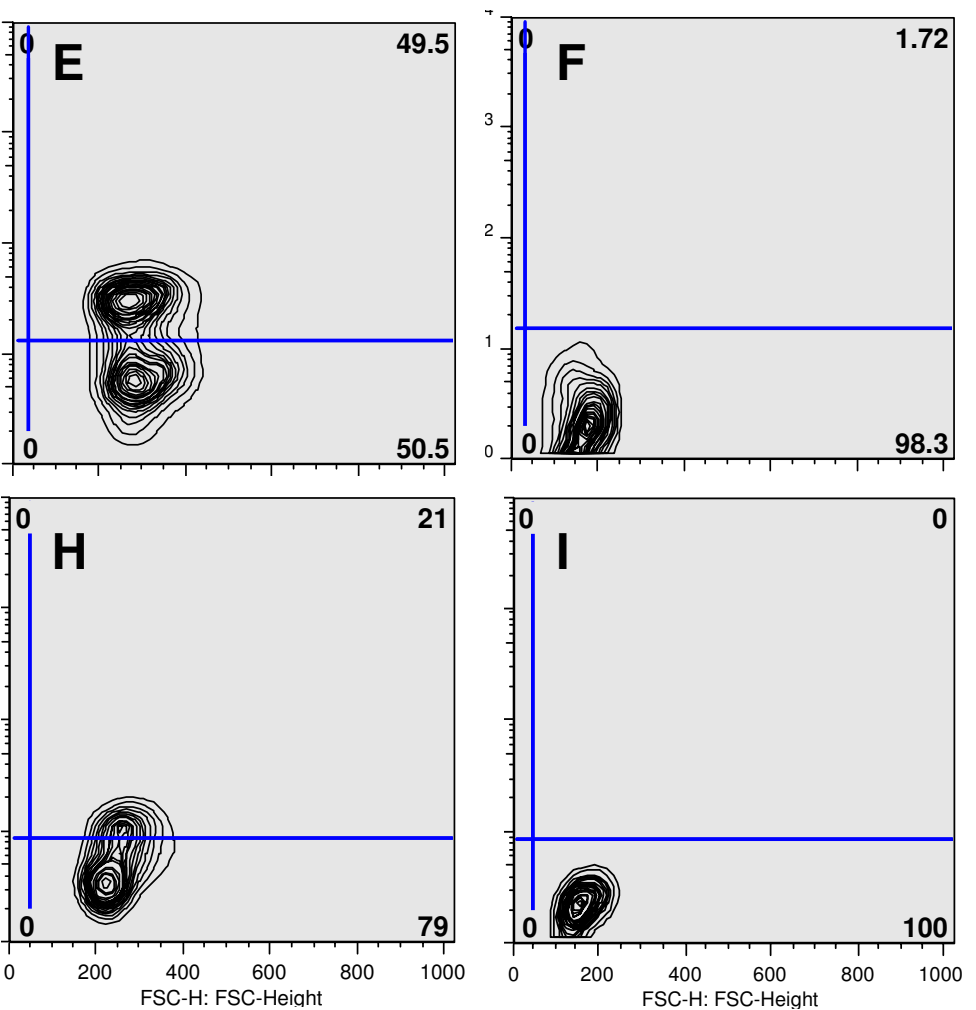

\section{Figure I}

Dot and contour plots showing DENV-Ag and iNOS monocyte and lymphocyte expression in dengue patients. Human PBMLs a from healthy individual (Figures IA,ID,IG) were used as control. Cells from a 4-day dengue infected patient (Figures IB, IC, IE, IF, IH, II) were labelled with anti-CDI4-PE and CDI4+ gated cells - RI (Figure IB) were considered as logical gate or monocyte gate and R2 is as the lymphocyte gate in the FCS vs. SSC dot plot (Figure IC). RI and R2 were used for further analysis during this work. Alternatively, human PBMLs were labelled either with an antibody to DENV Ags and anti-mouse IgG-PE (Figures ID-IF) or with anti-iNOS-FITC (Figures IG-II) and analysed by FACS in either the RI, monocyte gate (Figures ID-IF) or in the R2, lymphocyte gate (Figures IF-II). $x$-axis represent mean of cell population size (FCS) and $y$-axis represent cell granularity (SSC) or fluorescence intensity. 

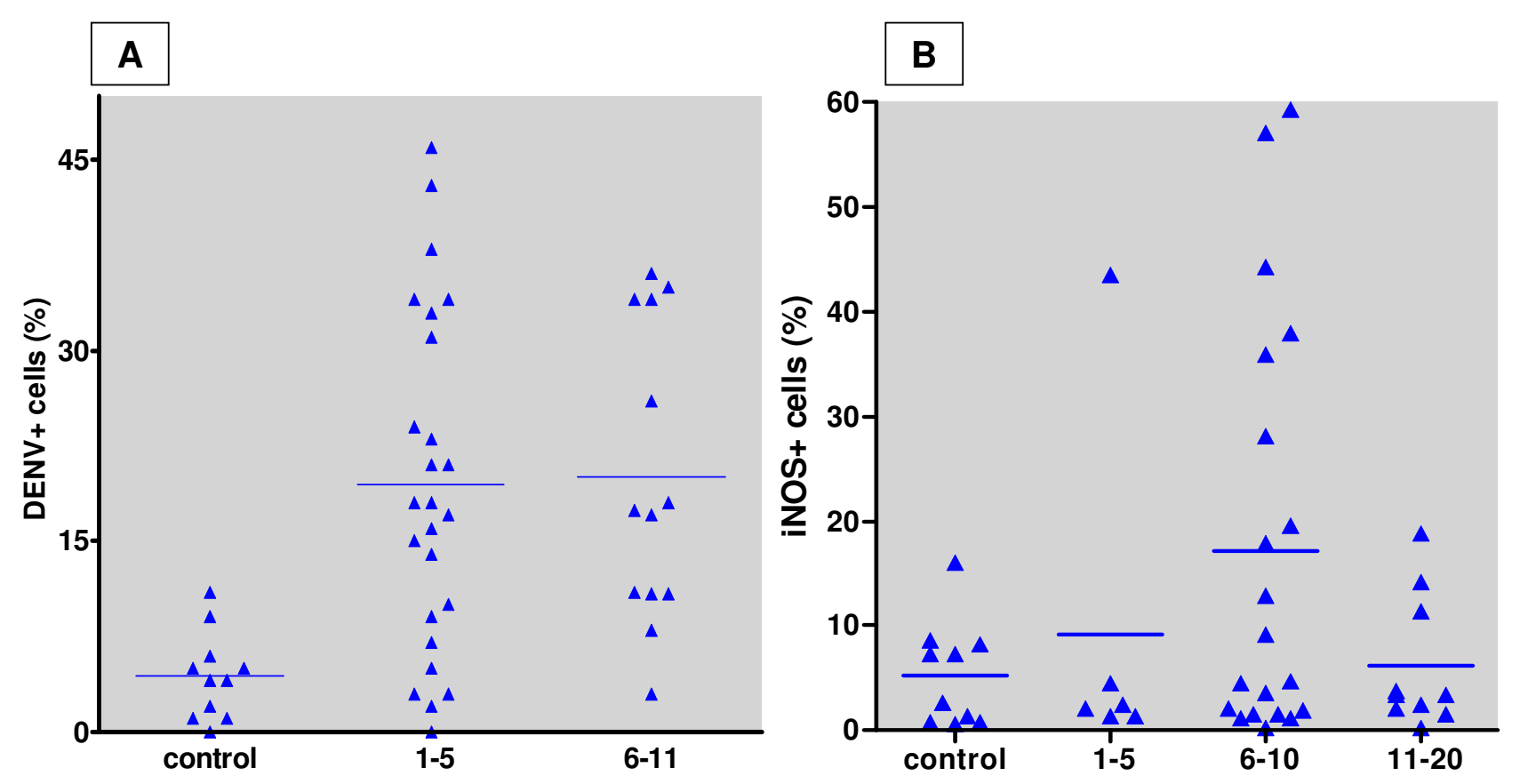

Time after disease onset (days)

\section{Figure 2}

Frequencies of DENVAg+ and iNOS+ monocytes in dengue patients. Human PBMLs from dengue individuals were labelled with an antibody to DENV-Ag and an anti-mouse IgG-PE or with an antibody to iNOS FITC-labelled and data obtained by FACS in the monocyte gate. Percentages of DENV-Ag+ infected cells were determined in II healthy individuals and 35 with dengue (Figure 2A; 2 patients were measured in duplicate samples at different time points). Percentages of iNOS+ infected cells were determined in 10 healthy individuals and 22 with dengue (Figure 2B; I4 patients were measured in duplicate samples at different time points). Horizontal lines represent percentage averages of labelled cells from the population of individuals in each of the discrete categories.

mononuclear leukocytes compared to the absence of fluorescent cells in control cells (Figure 3A). DENV-Ag+ cells were detected by flow cytometry among CD14+ cells, although very small rates of CD14-cells were also labelled for DENV-Ag (Figures 4A and 4B are labelling controls for Figure 4C). For further evaluations during in vitro infection, we studied the monocyte population, using the CD14+ logical gate, which presented the same profile as the R1 shown in Figure 1B).

In Figure 4D we observed that infected monocytes displayed specific DENV-Ag expression when compared to monocyte incubation with inactivated virus and an isotype-matched antibody, suggesting virus replication during infection. INOS was specifically expressed in monocytes infected with DENV. Mock-infected monocytes by inactivated DENV did not yield viral antigens during culture. The inactivated virus consistently induced low rates of INOS+ monocytes, however differences were statistically insignificant when compared to controls. The infectious virus in all experiments resulted in significantly higher rates of INOS+ monocytes than in control cultures. Infectious virus, if not crucial, certainly play an important role in inducing iNOS. Control cells displayed only low levels of background labelling for both DENV-Ag and iNOS.

During in vitro infection DENV-Ag were markedly expressed in monocytes and detected on day 3 either by confocal microscopy (Figure $3 \mathrm{~B}$ ) or by flow cytometry (Figure 4). However, from day 4 to 6 Ags detection disappeared rapidly (Figure 4E) with insignificant rates of labelled cells (Student's T-test). INOS is apparently detected in cells already at day 3, but it reaches significantly higher frequencies of positive cells at days 5 and 6 (Figure 4E). 

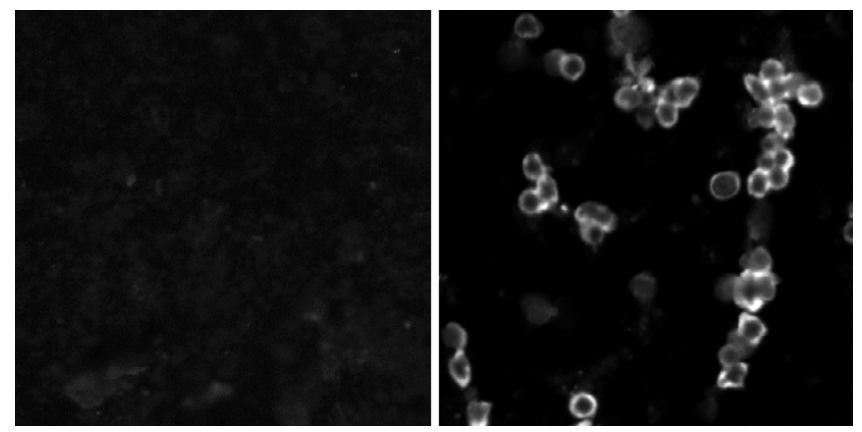

Figure 3

Confocal microscopy of DENV-Ag expression after in vitro infection of monocyte-rich cultures. Adherent human PBMLs were incubated for three days either with cell culture medium (Figure 3A, $189.5 \mu \mathrm{m} /$ field), or with infectious DENV (Figure 3B, $125 \mu \mathrm{m} /$ field). Cells were labelled with antibody to DENV-Ag and anti-mouse IgG-FITC.

DENV-Ag detection in infected cells after treatment with an iNOS inhibitor - NGMLA or with a NO donor - SNP

Nitric oxide antiviral activity induced by viruses in mononuclear phagocytes may be inhibited by N-monomethylL-arginine acetate (NGMLA) [28]. Monocyte-enriched cultures were treated with NGMLA and simultaneously infected with DENV. DENV-Ag+ cells were present in significantly higher frequency among infected cells in treated cultures after 4 days, as compared to infected and untreated cultures (Figure 5A, 5B). Figure 5A presents a flow cytometry histogram with an increased DENV-Ag+ cell population in presence of $N^{G}$ MLA treatment as compared to untreated infected cultures, with significantly higher percentages of labelled cells (Figure 5B). Thus, the inhibition of iNOS facilitates DENV-1 replication, suggesting that NO production might be involved in the control of virus replication.

Dengue virus has limited rates of infection in monocytes and after a few days infection is controlled accompanied by the induction of several factors that may act as inhibitors of viral replication [21,29]. Since C6/36 cells are extremely susceptible to DENV infection and allow intense virus replication, these mosquito cells should be suitable to test the effect of a potential antiviral molecule. Therefore, C6/36 cultures were infected with DENV and simultaneously treated with sodium nitroprussiate (SNP), a known NO donor, which was added at concentrations of 10 or $100 \mu \mathrm{M}$. After 2 days of infection and treatment, DENV-Ag+ cells were detected using FACS. An uninfected cell control was used in order to detect unspecific labelling. SNP induced a significant inhibition of DENV-Ag expression in infected C/36 cells in both tested concentra- tions, when percentages of positive cells were compared to those in untreated infected cells (analysis by Student's T test; Figures 5C and 5D). Therefore, inhibition of DENV1 replication by NO production is evident during the present experiments.

\section{Discussion}

DENV was detected for the first time by flow cytometry in peripheral monocytes of infected patients. Earlier reports demonstrated viral particles in monocytes, lymphocytes or endothelial cells from tissues and blood clot of patients $[9,30]$. Infectious DENV [3] or PCR detection of nucleic acid [7] in PBMLs were even at higher incidence than in serum. We did not detect viral antigens in lymphocytes despite others having done so [9,30]. This may be due to the viral strain used or alternatively the genetic constitution of the human PBML donors. Monocytes are important targets for DENV either in vitro [31] or in vivo [8]. Supporting our previous report [26], we present here that DENV likely replicates in monocytes since detected antigens increase with time and no antigen is detected when inactivated virus is used. This indicates that viruses probably replicate for a short period and, during cell infection, mechanisms are activated that are able to control further replication.

Interferon (IFN)-mediated antiviral action is still considered to be among the most important intracellular mechanisms against viruses, however recently a mechanism in which viral proteins might be involved in blocking IFN signalling during dengue virus infections has been described [32] supporting the conjecture that other complementary antiviral activities may be acting during dengue infection as well [33].

We have exhibited here that DENV can be detected in peripheral monocytes of patients with acute Dengue Fever, and that these cells are activated as demonstrated by the expression of iNOS studied ex vivo. Equivalent data was obtained with in vitro infected monocytes from healthy individuals, and virus presence can be modulated by inhibiting iNOS or generating NO in cell culture, indicating that this molecule is likely to have a role in controlling DENV-1 genome expression within monocytes.

During acute Dengue Fever, iNOS expression in monocytes differed among patients probably due to individual variations. Inducible NOS is encoded by the NOS2A gene, haplotype 2 is associated with self-limiting hepatitis $\mathrm{C}$ infections [34] and NO production was associated with less severe forms of dengue [19].

Viral replication inhibition by $\mathrm{NO}$ has been considered with even increasing importance. The ability of NO to inhibit virus replication was first described in 1993 

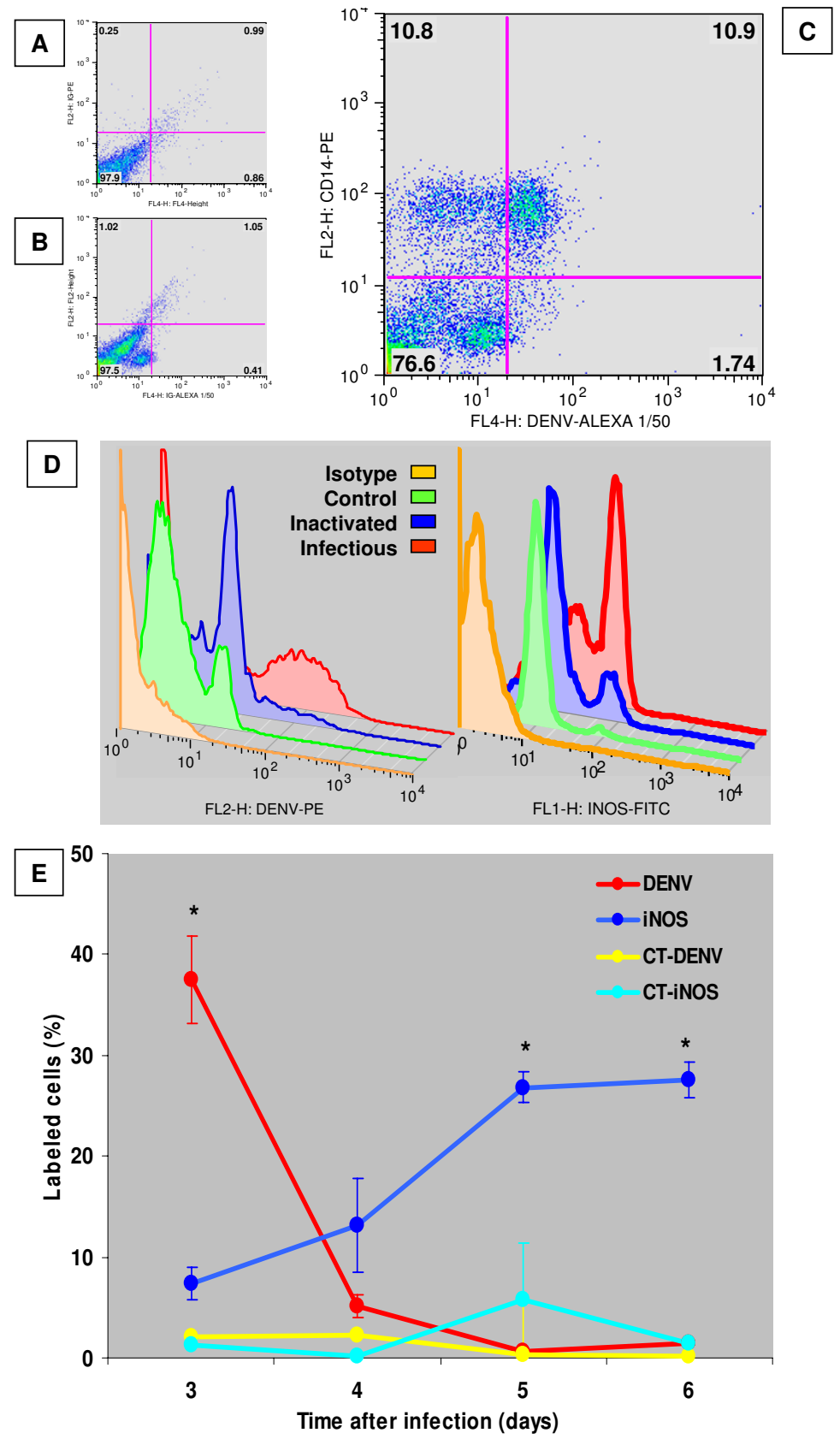

\section{Figure 4}

DENV-Ag and iNOS expression after in vitro Dengue infection of monocytes. Adherent human PBMLs were incubated for three days with infected DENV (Figures 4A, 4B and 4C). Cells were labelled either with isotype matched antibodies (Figures 6A and 6B) or antibodies to CDI4-PE ( $y$-axis) and DENV-Complex-Alexa-654 ( $x$-axis) and were analysed by FACS (Figure 4C, ungated). Cells incubated for three to six days with cell culture medium, inactivated DENV or infectious DENV were labelled with antibody to DENV-Ag and anti-mouse IgG-PE and/or anti-iNOS-FITC and analysed by FACS. Isotype matched antibodies were used for both labelings (Figure 4D, 3 days for DENV-Ag and 6 days for iNOS labelling). $x$-axis represent mean of fluorescence intensity and $y$-axis represent percentage of maximum cell number counts. Figure $4 \mathrm{E}$ shows a kinetic curve comparing DENV-Ag and iNOS expression on cells from the monocyte gate. Each point represent average \pm SEM percentages from samples set in triplicates. $* P<0.05$ and in Student's T-test showing difference in DENV-Ag and iNOS expression compared to uninfected controls (CT). Data are obtained from one representative experiment out of three performed with different cell donors. 


\section{Monocytes + iNOS inhibitor}
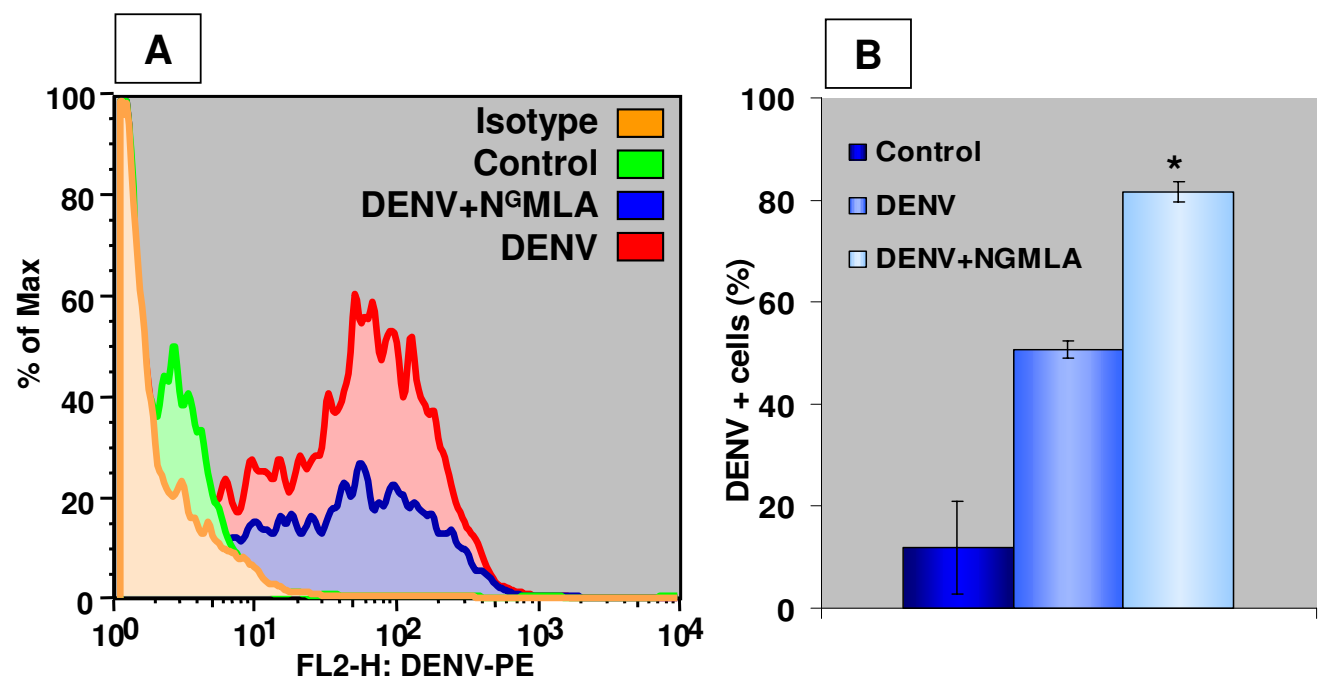

C6/36 Cells + NO donor
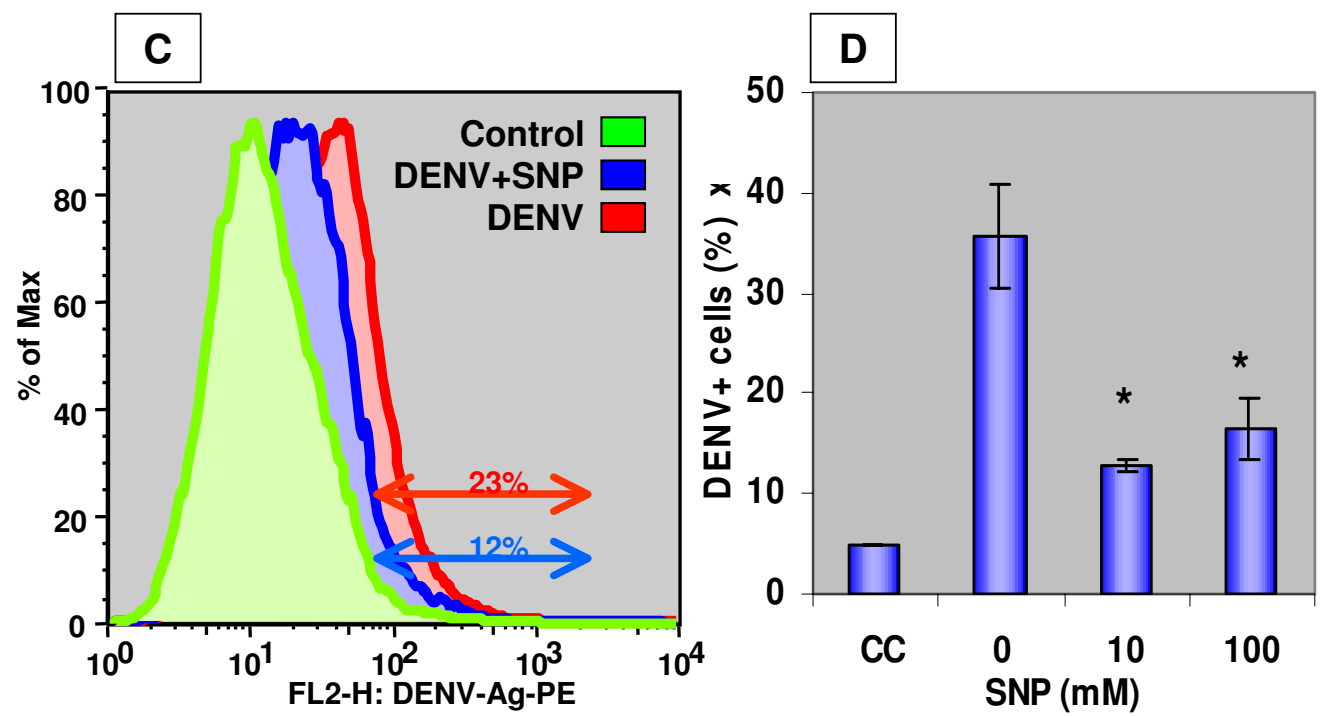

Figure 5

Effect of an iNOS inhibitor and of a NO donor on DENV-Ag expression after cell infection. Figures 5A and 5B Effect of iNOS inhibitor - NGMLA on monocyte infection. Adherent PBMLs were incubated with either Mock C6/36 cell supernatant or DENV inoculum for 4 days in presence or absence of $400 \mu M$ NGMLA. Figure $4 A$ shows histogram with profile of infected monocytes after NGMLA treatment and labelling controls. Figure 4B shows percentages of DENV-Ag+ in gated monocytes obtained by flow cytometry. Figures $5 \mathrm{C}$ and $5 \mathrm{D}$-. Effect of NO donor - SNP, on C6/36 cell infection. C6/36 cells were incubated with DENV for 2 days in absence or presence of 10 or $100 \mu M$ SNP. Figure 4C shows a histogram with profiles of infected C6/36 cells obtained by FACS from a culture treated with $10 \mu M$ SNP or controls. The histogram gates have been made where $\geq 99 \%$ than cells in the cell control are excluded. Figure 4Dshows percentages of DENV-Ag+ cells calculated from ungated cells after labelling with antibody to DENV-Complex and anti-mouse IgG-PE. In histograms $x$-axis represent mean of fluorescence intensity and $y$-axis represent percentage of maximum cell number counts. Cells were labelled with antibody to DENV-Complex followed by anti-mouse IgG-PE. Average \pm SEM are represented from samples set in triplicates. $* P<0.05$ in Student's T-test showing difference in DENV infection after treatment. Data are obtained from one representative experiment out of two for each cell type using two different monocyte donors. 
$[33,35,36]$ and thereafter many other studies have been developed. While some viruses were reported to be susceptible to NO action, others were resistant [35]. The mechanisms by which $\mathrm{NO}$ induces viral modulation are diverse, such as inactivation of viral cysteine protease by NO-dependent S-nitrosylation [36] or inhibition of Epstein-Barr virus reactivation. The inhibition of virus replication by $\mathrm{NO}$ was found to be mediated by IFN- $\gamma$ $[33,37]$ and dependent upon the induction of the signal transducer and activator of transcription (STAT) STAT1 phosphorylation [38]. Antiviral NO-mediated effect may also be activated by IFN- $\alpha$, since it has been observed that mononuclear leukocytes activated in vitro by IFN- $\alpha$ or from Hepatitis $\mathrm{C}$ virus infected patients undergoing IFN- $\alpha$ therapy produce NO [39]. Some flaviviruses had their NO susceptibility tested and an effective inhibitory mechanism was determined for Japanese encephalitis virus [40], but studies on Tick-borne encephalitis virus (TBE-V) revealed no antiviral effects by NO [35]. The fact that dengue patients may have monocytes activated by circulating IFN- $\gamma[12-14]$ is consistent with induction of iNOS during acute disease as reported here for both in vivo and in vitro infection.

NO may play a role in severity of viral hemorrhagic fevers(Sanchez et al., 2004) probably when produced in high concentrations, by affecting vascular tone and contributing to virus-induced shock. As previously mentioned, NO was detected in sera from patients with dengue [19] and correlated with the less severe form of the disease. Hence, NO may be exerting both protective and pathological action, depending upon the concentration produced [41]. Since our panel consisted of few patients, a correlation was not possible; iNOS+ cell rates were increased in some patients from both groups presenting mild or severe disease. Espina et al. [21] were not able to detect NO production by monocytes in culture. This apparent contradiction with our data of induced NOS may be explained by the use of a diferent detection technique: Griess reagent detects nitrite in cell culture supernatant which may be below method sensitivity since the density of monocytes in culture is not high. We did not succeed in detecting NO by this method in human monocyte cultures, and we only detected NO in murine macrophages after proper stimulation at high cell culture density [20]. Moreover, detection of NO produced in vitro by infected Kupffer cells [20] was carried out by a fluorimetric assay, much more sensitive than the Griess Reaction.

Only few reports show human mononuclear cells from healthy individuals generating NO production following treatment with cytokines, pathogens, and/or pathogenderived products $[39,42]$. Until a few years ago expression of iNOS in humans was questioned [43] or difficult to detect $[20,44]$. It may be possible that iNOS induction and expression dependent on synergistic signals to macrophage/monocyte $[45,46]$, and cytokines and virus products may be acting as different stimuli.

Replicating dengue viruses may be necessary for optimal iNOS induction, since rates of iNOS+ cells were much higher than when the inactivated virus was used. However, Kupffer cells infected with DENV induced NO and iNOS, in spite of the absence of viral progeny. Non-living products, such as peptides [47], originating from either other viruses $[39,48]$ or parasites $[49,50]$ can stimulate iNOS in macrophages/ monocytes and induce NO production.

Our data demonstrate that, when experimentally infecting their targets (e.g., monocytes), DENV-1 is able to induce a progressive expression of the enzyme iNOS, indicating that $\mathrm{NO}$ might be produced during in vitro infection as it is produced in vivo. At 6 days of infection, the iNOS detection is increased as compared to that of 3 days and is coincident with the DENV decrease, favouring the hypothesis that iNOS ${ }^{+}$cells were promoting an inhibitory effect on viruses either directly by NO production or by other virus-induced mechanisms during this monocyte activation, such as IFN- $\alpha$ production [39]. Alternatively cells interacting with viral antigens are probably becoming activated and dying either by cell lysis or by virus induced apoptosis [21]. We also observed that surviving cells remained in culture for more than 10 days : either viruses are eliminated or cells become refractory by interferon-related mechanisms, in contrast with what is observed, e.g., for mosquito C6/36 cells, which are mostly destroyed by the virus. Here we observed that there is an enhancement of DENV-1 Ags detection, when infected monocytes were cultured with the iNOS inhibitor $N^{G} M L A$, indicating that DENV-1 is very likely susceptible to NO inhibitory activity. This result is confirmed by the observation that DENV-1 detection is strongly inhibited in C6/36 cultures by the presence of the NO donor, SNP. These findings are similar and supported by observations in other viral models [51].

With regard to DENV replication, further studies are warranted in order to elucidate which pathways are involved in NO-mediated inhibition of DENV-1. Despite C6/36 remain viable by Trypan blue or propide iodine exclusions, it has to be considered that the NO action in virus targeted cells may involve apoptosis. Furthermore, it is not known whether or not other strains and serotypes will activate iNOS and be sensitive to NO action. There may be relevance in studying various strains from different serotypes and evaluate if susceptibility and resistance are strain and/or serotype specific. 


\section{Conclusion}

The data presented here displays for the first time the presence of iNOS in monocytes from patients with acute dengue fever. Despite the fact that, in excess, NO may provide a deleterious effect on vascular permeability, evidence exhibited here favour a role for NO in the control of in vitro dengue infection within monocytes. This may hold true for natural human infection as well.

\section{Competing interests}

The author(s) declare that they have no competing interests.

\section{Authors' contributions}

PCFNS and ELA participated equally in the study design, in the experimental work and in the preparation of the manuscript.

PCFNS carried out all the in vitro infections and assays and flow cytometry analysis.

ELA carried out all the work with patient blood collecting, storing cells and plasma and performing flow cytometry assays and analysis.

SMOZ established the connection with the Health Units in Niterói, examined the patients and registered the clinical data.

RVS examined the patients and registered the clinical data.

SRNIR helped with patient blood collecting, storing cells and plasma.

DISC helped to perform flow cytometry assays.

RMRN was responsible for the confirmatory diagnosis of dengue in Rio de Janeiro.

CFK oversaw the study and participated in its design and coordination, performed flow cytometry and statistical analysis and prepared the initial and revised drafts of the manuscript and figures.

\section{Acknowledgements}

Oswaldo Cruz Foundation (FIOCRUZ), Brazilian National Council for Research (CNPq) and Rio de Janeiro State Research Support Foundation (FAPERJ) financially supported this work. P.C.F Neves-Souza and D.I.S. Cerqueira were fellows from $C N P q$ and $E L$ Azeredo was a pre-doctoral fellow from FIOCRUZ. We acknowledge the Dr. E Pozzolo and Dr. Gilbert (Secretaria Municipal de Saúde de Foz do Iguaçu) for their support during the fieldwork and confirmatory diagnostics in Paraná, Brazil in 2000. We thank Dr. Marize Miagostovich and Ms. Eliana Saraiva for their assistance during laboratorial diagnosis in our Departament, Dr. Marcelo PelajoMachado from Departmento de Patologia, IOC for the confocal microscopy and the technical support of Ms. Farid O F Von Sydow, as graduate student from Instituto de Microbiologia, UFRJ, and Maryrose Lavatori and Mariana de Sousa Lopes and Mr. Mitchell R Lishon for the language revision.

\section{References}

I. Halstead SB: Pathogenesis of dengue: challenges to molecular biology. Science 1988, 239(4839):476-48I.

2. Monath TP: Pathobiology of the Flaviviruses. In he Togaviridae and Flaviviridae Edited by: Schlesinger SSMJ. New York, Plenun Press; 1986:375-440.

3. Scott RM, Nisalak A, Cheamudon U, Seridhoranakul S, Nimmannitya $\mathrm{S}$ : Isolation of dengue viruses from peripheral blood leukocytes of patients with hemorrhagic fever. J Infect Dis 1980, I4I(I): I-6.

4. Tassaneetrithep B, Burgess TH, Granelli-Piperno A, Trumpfheller C, Finke J, Sun W, Eller MA, Pattanapanyasat K, Sarasombath S, Birx DL, Steinman RM, Schlesinger S, Marovich MA: DC-SIGN (CD209) Mediates Dengue Virus Infection of Human Dendritic Cells. J Exp Med 2003, I 97(7):823-829.

5. Wu SJ, Grouard-Vogel G, Sun W, Mascola JR, Brachtel E, Putvatana R, Louder MK, Filgueira L, Marovich MA, Wong HK, Blauvelt A, Murphy GS, Robb ML, Innes BL, Birx DL, Hayes CG, Frankel SS: Human skin Langerhans cells are targets of dengue virus infection. Nat Med 2000, 6(7):8I6-820.

6. Morens DM, Marchette NJ, Chu MC, Halstead SB: Growth of dengue type 2 virus isolates in human peripheral blood leukocytes correlates with severe and mild dengue disease. $\mathrm{Am} J$ Trop Med Hyg 1991 , 45(5):644-65I.

7. Wang HL, Lin KH, Yueh YY, Chow L, Wu Y, Chen HY, Sheu MM, Chen WJ: Efficient diagnosis of dengue infections using patients' peripheral blood leukocytes and serum/plasma. Intervirology 2000, 43: I07-III.

8. Azeredo EL, Reis SRIN, Zagne SMO, Miagostovich M, Nogueira RM, Kubelka CF: Detection of dengue virus in peripheral mononuclear cells from patients using flow cytometry: Mangaratiba, Rio de Janeiro, Brazil. ; 2003.

9. Jessie K, Fong MY, Devi S, Lam SK, Wong KT: Localization of dengue virus in naturally infected human tissues, by immunohistochemistry and in situ hybridization. J Infect Dis 2004, I89(8): 14||$-|4| 8$.

10. Rothman AL, Ennis FA: Immunopathogenesis of Dengue hemorrhagic fever. Virology 1999, 257(I): 1-6.

II. Guidotti LG, Chisari FV: Noncytolytic control of viral infections by the innate and adaptive immune response. Annu Rev Immunol 200I, 1 9:65-9I.

12. Azeredo EL, Zagne SM, Santiago MA, Gouvea AS, Santana AA, NevesSouza PC, Nogueira RM, Miagostovich MP, Kubelka CF: Characterisation of lymphocyte response and cytokine patterns in patients with dengue fever. Immunobiology 200I, 204(4):494-507.

13. Green S, Vaughn DW, Kalayanarooj S, Nimmannitya S, Suntayakorn S, Nisalak A, Lew R, Innis BL, Kurane I, Rothman AL, Ennis FA: Early immune activation in acute dengue illness is related to development of plasma leakage and disease severity. J Infect Dis I999, I 79(4):755-762.

14. Kurane I, Innis BL, Nisalak A, Hoke C, Nimmannitya S, Meager A, Ennis FA: Human $T$ cell responses to dengue virus antigens. Proliferative responses and interferon gamma production. Clin Invest 1989, 83(2):506-5I 3.

15. Kurane I, Ennis FA: Production of interferon alpha by dengue virus-infected human monocytes. J Gen Virol 1988, 69 ( Pt 2):445-449.

16. Akaike TMH: Nitric oxide and virus infection. Immunology 2000, I 0 I (3):300-308.

17. Chen RF, Yeh WT, Yang MY, Yang KD: A model of real-time correlation of viral titers with immune reactions in antibodydependent enhancement of Dengue-2 infections. FEMS Immunol Med Microbiol 200I, 30(I): I-7.

18. Jiang $H$, Stewart CA, Leu RW: Tumor-derived factor synergizes with IFN-gamma and LPS, IL-2 or TNF-alpha to promote macrophage synthesis of TNF-alpha and TNF receptors for autocrine induction of nitric oxide synthase and enhanced nitric oxide-mediated tumor cytotoxicity. Immunobiology 1995 , I 92(5):321-342. 
19. Valero N, Espina LM, Anez G, Torres E, Mosquera JA: Short report: increased level of serum nitric oxide in patients with dengue. Am J Trop Med Hyg 2002, 66(6):762-764.

20. Marianneau P, Steffan AM, Royer C, Drouet MT, Jaeck D, Kirn A, Deubel V: Infection of primary cultures of human Kupffer cells by Dengue virus: no viral progeny synthesis, but cytokine production is evident. J Virol 1999, 73(6):520I-5206.

21. Espina LM, Valero NJ, Hernandez JM, Mosquera JA: Increased apoptosis and expression of tumor necrosis factor-alpha caused by infection of cultured human monocytes with dengue virus. Am J Trop Med Hyg 2003, 68(I):48-53.

22. Reed LJ, Muench $\mathrm{H}$ : A simple method of estimating fifty per cent endpoints. Am J Hyg 1938, 27:493-497.

23. Miagostovich MP, Nogueira RM, Cavalcanti SM, Marzochi KB, Schatzmayr HG: Dengue epidemic in the state of Rio de Janeiro, Brazil: virological and epidemiological aspects. Rev Inst Med Trop Sao Paulo 1993, 35(2): 149-154.

24. Schoepp RJ, Beaty BJ: Titration of dengue viruses by immunofluorescence in microtiter plates. J Clin Microbiol 1984 , 20(5): $1017-1019$.

25. Akarid K, Sinet M, Desforges B, Gougerot-Pocidalo MA: Inhibitory effect of nitric oxide on the replication of a murine retrovirus in vitro and in vivo. J Virol 1995, 69(I I):700 I-7005.

26. Sydow FF, Santiago MA, Neves-Souza PC, Cerqueira DI, Gouvea AS, Lavatori MF, Bertho AL, Kubelka CF: Comparison of dengue infection in human mononuclear leukocytes with mosquito C6/36 and mammalian Vero cells using flow cytometry to detect virus antigen. Mem Inst Oswaldo Cruz 2000, 95(4):483-489.

27. Cologna R, Rico-Hesse R: American genotype structures decrease dengue virus output from human monocytes and dendritic cells. J Virol 2003, 77(7):3929-3938.

28. Benencia F, Courreges MC: Nitric oxide and macrophage antiviral extrinsic activity. Immunology 1999, 98(3):363-370.

29. Chen YC, Wang SY: Activation of terminally differentiated human monocytes/macrophages by dengue virus: productive infection, hierarchical production of innate cytokines and chemokines, and the synergistic effect of lipopolysaccharide. I Virol 2002, 76(19):9877-9887.

30. Lin YW, Wang KJ, Lei HY, Lin YS, Yeh TM, Liu HS, Liu CC, Chen SH: Virus replication and cytokine production in dengue virusinfected human B lymphocytes. J Virol 2002, 76(23): I2242-12249.

31. Halstead SB, Porterfield JS, O'Rourke EJ: Enhancement of dengue virus infection in monocytes by flavivirus antisera. Am J Trop Med Hyg 1980, 29(4):638-642.

32. Munoz-Jordan JL, Sanchez-Burgos GG, Laurent-Rolle M, Garcia-Sastre $A$ : Inhibition of interferon signaling by dengue virus. Proc Natl Acad Sci U S A 2003, I00(24): I 4333-I4338.

33. Karupiah G, Xie QW, Buller RM, Nathan C, Duarte C, MacMicking JD: Inhibition of viral replication by interferon-gammainduced nitric oxide synthase. Science 1993, 26I(5 I27 ): $1445-$ I 448

34. Yee LJ, Knapp S, Burgner D, Hennig BJ, Frodsham AJ, Wright M, Thomas HC, Hill AV, Thursz MR: Inducible nitric oxide synthase gene (NOS2A) haplotypes and the outcome of hepatitis C virus infection. Genes Immun 2004, 5(3): I83-187.

35. Kreil TR, Eibl MM: Nitric oxide and viral infection: NO antiviral activity against a flavivirus in vitro, and evidence for contribution to pathogenesis in experimental infection in vivo. Virology 1996, 21 (1):304-306.

36. Saura M, Zaragoza C, McMillan A, Quick RA, Rohenadl C, Lowenstein JM, Lowenstein CJ: Antiviral mechanims of nitric oxide: inhibition of viral proteinase. Immunity 1999, 10:21-28.

37. MacLean A, Wei XQ, Huang FP, Al-Alem AH, Chan WL, Liew FY: Mice lacking inducible nitric-oxide synthase are more susceptible to herpes simplex virus infection despite enhanced ThI responses. J Gen Virol 1998, 79:825-830.

38. Chesler DA, Dodard C, Lee GY, Levy DE, Reiss CS: Interferongamma-induced inhibition of neuronal vesicular stomatitis virus infection is STATI dependent. I Neurovirol 2004 , I0(I):57-63.

39. Sharara AI, Perkins DJ, Misukonis MA, Chan SU, Dominitz JA, Weinberg JB: Interferon (IFN)-alpha activation of human blood mononuclear cells in vitro and in vivo for nitric oxide synthase (NOS) type 2 mRNA and protein expression: possible relationship of induced NOS2 to the anti-hepatitis C effects of IFN-alpha in vivo. J Exp Med 1997, I86(9): I495-I502.

40. Lin YL, Huang YL, Ma SH, Yeh CT, Chiou SY, Chen LK, Liao CL: Inhibition of Japanese encephalitis virus infection by nitric oxide: antiviral effect of nitric oxide on RNA virus replication. J Virol 1997, 7 I(7):5227-5235.

41. Wolkow PP: Involvement and dual effects of nitric oxide in septic shock. Inflamm Res 1998, 47(4): I52-166.

42. Weinberg JB, Misukonis MA, Shami PJ, Mason SN, Sauls DL, Dittman WA, Wood ER, Smith GK, McDonald B, Bachus KE, et al.: Human mononuclear phagocyte inducible nitric oxide synthase (iNOS): analysis of iNOS mRNA, iNOS protein, biopterin, and nitric oxide production by blood monocytes and peritoneal macrophages. Blood 1995, 86(3): I I84-I| 95.

43. Denis M: Human monocytes/macrophages: NO or no NO? Leukoc Biol 1994, 55(5):682-684.

44. Gantt KR, Goldman TL, McCormick ML, Miller MA, Jeronimo SM, Nascimento ET, Britigan BE, Wilson ME: Oxidative responses of human and murine macrophages during phagocytosis of Leishmania chagasi. J Immunol 200I, I67(2):893-90I.

45. Jaramillo $\mathrm{M}, \mathrm{Naccache} \mathrm{PH}$, Olivier M: Monosodium urate crystals synergize with IFN-gamma to generate macrophage nitric oxide: involvement of extracellular signal-regulated kinase I/ 2 and NF-kappa B. J Immunol 2004, I72(9):5734-5742.

46. Plum J, Huang C, Grabensee B, Schror K, Meyer-Kirchrath J: Prostacyclin enhances the expression of LPS/INF-gamma-induced nitric oxide synthase in human monocytes. Nephron 2002, 9l(3):39|-398.

47. Perez-Mediavilla LA, Lopez-Zabalza MJ, Calonge M, Montuenga L, Lopez-Moratalla N, Santiago E: Inducible nitric oxide synthase in human lymphomononuclear cells activated by synthetic peptides derived from extracellular matrix proteins. FEBS Lett 1995, 357(2): $121-124$

48. Imanishi N Andoh $T$, Sakai $S$, Satoh $M$, Katada $Y$, Ueda $K$, Terasawa $\mathrm{K}$, Ochiai H: Induction of Inducible Nitric Oxide (NO) Synthase mRNA and NO Production in Macrophages Infected with Influenza A/PR/8 Virus and Stimulated with Its EtherSplit Product. Microbiol Immunol 2005, 49(I):4I-48.

49. Camargo MM, Andrade AC, Almeida IC, Travassos LR, Gazzinelli RT: Glycoconjugates isolated from Trypanosoma cruzi but not from Leishmania species membranes trigger nitric oxide synthesis as well as microbicidal activity in IFN-gammaprimed macrophages. J Immunol I997, I59(12):6131-6139.

50. Keller CC, Kremsner PG, Hittner JB, Misukonis MA, Weinberg JB, Perkins $D$ J: Elevated nitric oxide production in children with malarial anemia: hemozoin-induced nitric oxide synthase type 2 transcripts and nitric oxide in blood mononuclear cells. Infect Immun 2004, 72(8):4868-4873.

5I. Rimmelzwaan GF, Baars MMJW, Lijster P, Fouchier RAM, Osterhaus ADME: Inhibition of influenza virus replication by nitric oxide. J Virol 1999, 73:8880-8883.

\section{Pre-publication history}

The pre-publication history for this paper can be accessed here:

http://www.biomedcentral.com/1471-2334/5/64/prepub 